\title{
Gastroscope guidewire volvulus tube decompression
}

Authors:

Sofoklis Panteleimonitis ${ }^{1,2}$, Guy Nash ${ }^{1}$

Affiliations:

1. Poole Hospital NHS Trust, Longfleet road, Poole, BH15 2JB, United Kingdom

2. University of Portsmouth, School of Health Sciences and Social Work, James Watson West, 2 King Richard $1^{\text {st }}$ road, Portsmouth, PO1 2FR, United Kingdom

Corresponding author:

Mr Sofoklis Panteleimonitis

Phone: $00447721773383 \quad$ Email: sofoklis_p@hotmail.com

ORCID ID: 0000-0003-3610-1201

Key words: sigmoid volvulus; volvulus decompression; gastroscope 


\section{Trick of the trade:}

Acute sigmoid volvulus is a surgical emergency [1]. Any delay in treatment increases the risk of bowel ischaemia, perforation, faecal peritonitis and death. The majority of patients can be successfully treated with non-operative decompression but elective definitive surgery has been recommended as most volvuli recur [2]. We describe a new technique for treating a sigmoid volvulus.

Traditionally with the patient in the left lateral position, decompression may be possible by passing a flatus tube alongside a flexible sigmoidoscope [3]. Usually there is a rush of liquid faeces and flatus with relief of the obstruction. The tube may be left in place for at least 24 hours to maintain decompression, prevent recurrence and give time for the bowel wall to recover. However, it is uncomfortable to have both tubes in the anus and the flatus tube often coils in the rectum. Alternatively, by withdrawing the sigmoidoscope (once it has achieved deflation of the sigmoid) and placing the flatus tube afterwards risks it not reaching the sigmoid, which may falsely reassure us whilst the tube is in the rectum. Converting an acute to a semi-elective operation is the aim of deflation. The flatus tube may be left until a definitive plan, which may include surgery [4] or the reduced mortality of fixation of the colon endoscopically (PEC) [5] is agreed.

We describe a novel alternative that has been used successfully to place a decompressing flatus tube with less pain and greater accuracy. In a patient not needing sedation it is possible to place a paediatric gastroscope (figure 1) through the lumen of a flatus tube and passing this single (combined; see figure 2) tube anally allows the accurate identification and placement of the flatus tube ensuring decompression as soon as the gastroscope is withdrawn to allow gas to pass. This technique has been used at our centre with success. The flatus tube may be kept in for some days by sticking it to his buttock with tape to avoid dislodgement, whilst definitive treatment is considered. 


\section{Disclosures}

Mr Sofoklis Panteleimonitis and Mr Guy Nask have no conflicts of interest or financial ties to disclose.

\section{Ethical approval}

All procedures performed in studies involving human participants were in accordance with the ethical standards of the institutional and/or national research committee and with the 1964 Helsinki declaration and its later amendments or comparable ethical standards. This type of study does not require formal ethical approval. All patients having this procedure sign an informed consent form before having the procedure. No patient data or characteristics were used for this study.

\section{Funding}

This study received no funding.

\section{References:}

1. Tan K-K, Chong C-S, Sim R (2010) Management of acute sigmoid volvulus: an institution's experience over 9 years. World J Surg 34:1943-1948. doi: $10.1007 / \mathrm{s} 00268-010-0563-8$

2. Raveenthiran V, Madiba TE, Atamanalp SS, De U (2010) Volvulus of the sigmoid colon. Colorectal Dis 12:e1-17. doi: 10.1111/j.1463-1318.2010.02262.x

3. Safioleas M, Chatziconstantinou C, Felekouras E, et al (2007) Clinical considerations and therapeutic strategy for sigmoid volvulus in the elderly: a study of 33 cases. World J Gastroenterol 13:921-924.

4. Suleyman O, Kessaf AA, Ayhan KM (2012) Sigmoid volvulus: long-term surgical outcomes and review of the literature. S Afr J Surg 50:9-15.

5. Frank L, Moran A, Beaton C (2016) Use of percutaneous endoscopic colostomy (PEC) to treat sigmoid volvulus: a systematic review. Endosc Int open 4:E737-41. doi: $10.1055 / \mathrm{s}-0042-106957$ 
Figure 1. Paediatric gastroscope passed through the lumen of a flatus tube

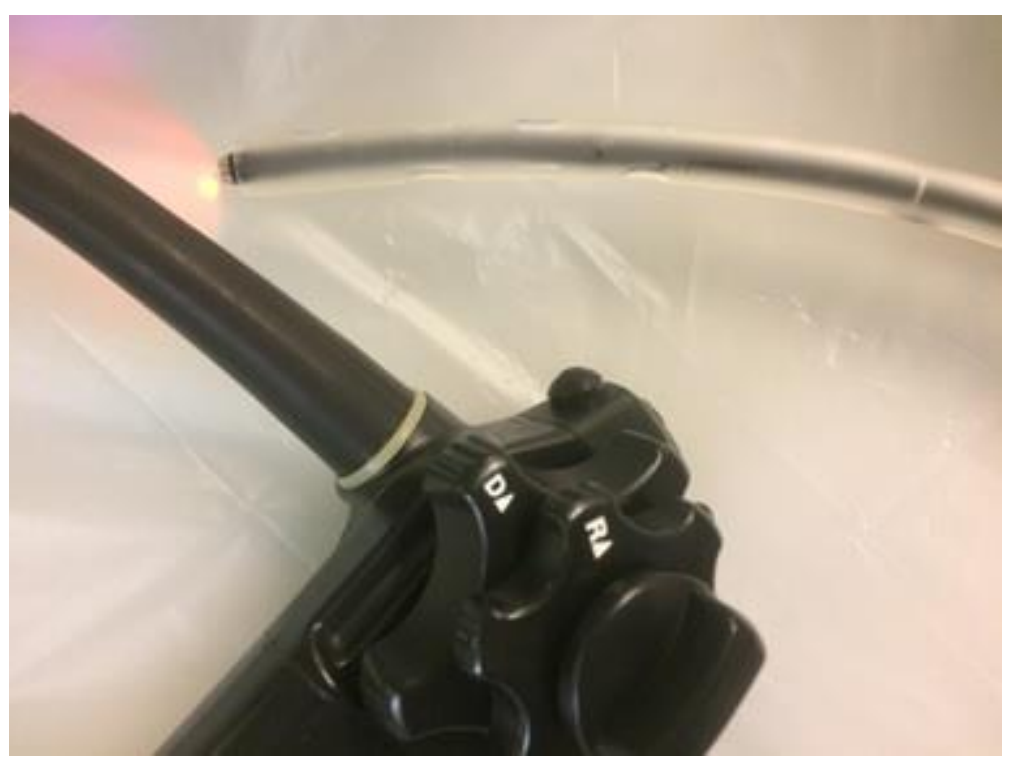

Figure 2. The end of the gastroscope is fitted just outside the end of the flatus tube during insertion

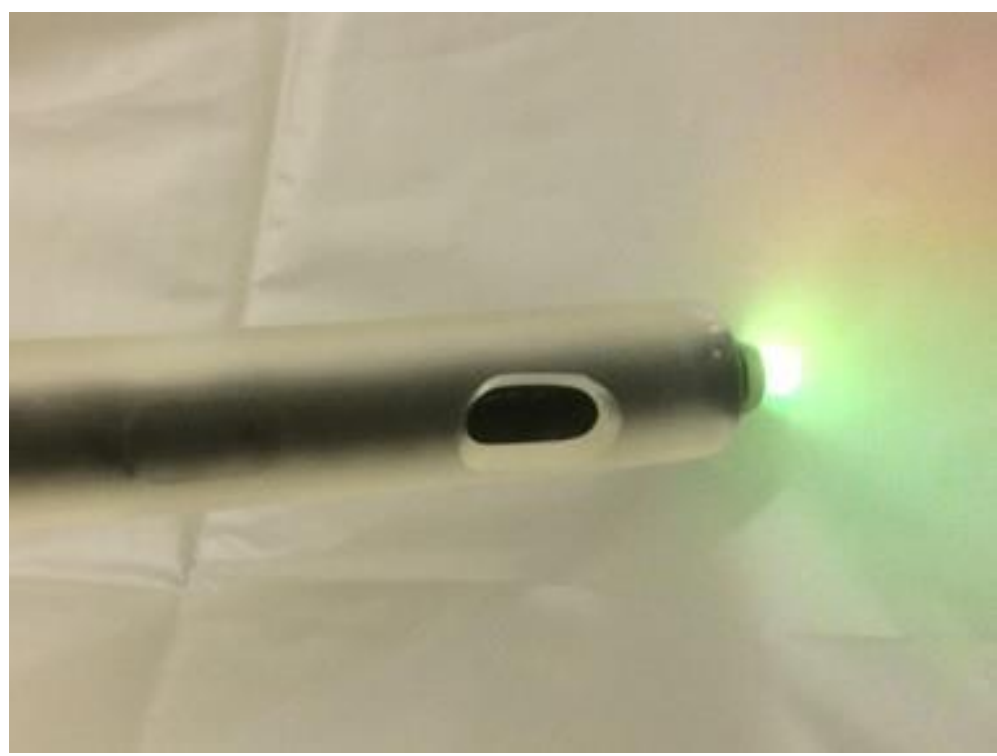

